\title{
Impact of Continuous Drying Method on Drying Quality of Southern Pine Sawn Timber
}

\author{
Chandan Kumar, ${ }^{\mathrm{a}, \mathrm{c}, *}$ Adam Faircloth, ${ }^{\mathrm{a}}$ William Leggate, ${ }^{\mathrm{a}}$ and Adam Redman ${ }^{\mathrm{b}}$ \\ The continuous drying of timber is attracting increasing international \\ interest for softwood drying because of several reported advantages, e.g., \\ improved energy efficiency and improved grade recovery. This study \\ aimed to investigate the impact of continuous drying kiln technology on the \\ quality of dried Queensland plantation-grown southern pine timber, \\ compared to the current ultra-high temperature batch drying process \\ adopted by many softwood processors. End matched boards were dried \\ using continuous and high-temperature drying schedules. The moisture \\ content and moisture gradient of each board was assessed in accordance \\ with AS/NZS standard 1080.1 (2012), AS/NZS standard 2796.3 (1999), \\ respectively, while the drying stress was assessed in accordance with \\ AS/NZS standard 4787 (2001). The boards dried with continuous drying \\ schedules resulted in slightly lower bow and spring values and similar cup \\ and twist values compared to the high temperature dried boards. The \\ moisture gradient and drying stress were significantly lower in boards \\ using continuous drying kiln technology compared to the high temperature \\ dried boards. This study will allow the Australian softwood industry to \\ better understand the dried timber quality obtained using new continuous \\ drying technology to make informed investment decisions.
}

DOI: 10.15376/biores.17.1.574-591

Keywords: Seasoning; Drying quality; Distortion; Moisture gradient; Drying stress; Warp, Australian softwood; Pine; High temperature drying

Contact information: a: Queensland Department of Agriculture and Fisheries, Horticulture and Forestry Science, Salisbury Research Facility, 50 Evans Rd, Salisbury Qld 4107 Australia; b: Burapha AgroForestry Co. Ltd. 23 Singha Rd. Ban Phonexay, Saysettha District P.O. Box 11834 Vientiane 01000 Lao PDR; c: University of Southern Queensland, Toowoomba, Australia;

*Corresponding author: chandan.kumar@daf.qld.gov.au

\section{INTRODUCTION}

The drying of timber is essential for the majority of applications, e.g., before machining, processing, and the end-use of timber. Drying provides dimensional stability and improves mechanical properties, e.g., stiffness and hardness, and reduces biological attacks, e.g., mould and fungal growth. Moreover, drying removes enormous amounts of water from timber, thus reducing the mass and volume, which ultimately reduces shipping and handling costs. Drying also improves joining by nails, screws, bolts, and adhesives as well as improves machining and processing efficiency. However, drying is one of the most energy-intensive processes out of all the industrial operations, consuming up to $15 \%$ of all industrial energy usage (Kumar et al. 2014). Drying can consume up to $70 \%$ of the energy and $90 \%$ of the total time on all processes per log when converting green logs to finished dried wood components, depending upon the species and product type (Redman 2004; Leggate et al. 2020). Therefore, drying is one of the most critical processing components 
in the timber supply chain.

Drying quality is determined by the number of defects that are developed during the drying process that lower the grade and intended value of the product. Various types of defects can occur during drying, e.g., distortion, internal stress, over-drying and underdrying, moisture gradient, and internal and surface checking. Drying quality reduction costs the softwood and hardwood timber industries millions of dollars in lost value and lost volume caused by poor product performance (Ward and Simpson 1997). Estimates suggest that up to $10 \%$ degradation can occur in dried wood due to the drying process because of checking, collapse, distortion, and moisture variation (Redman 2004). For example, improper moisture content in dried pine lumber can lead to losses between $\$ 1.2 / \mathrm{m}^{3}$ and $\$ 2.8 / \mathrm{m}^{3}$ and poor warp control losses between 50 dollars and 150 dollars per thousand board feet (MBF) or approximately between $\$ 21$ and $\$ 42 / \mathrm{m}^{3}$ (Shmulsky et al. 2005; Bond and Espinoza 2016). The drying operation is often blamed when unexpected defects appear in dried wood products (Ward and Simpson 1997).

Total elimination of drying-related degradation is not possible; however, various measures, e.g., the development of a suitable drying schedule and using innovative drying technologies (continuous drying, vacuum drying, and radio-frequency drying) have been applied to reduce the negative impact on quality during drying (Kumar and Karim 2017; Rabidin et al. 2017; Redman 2017). One such technology is continuous drying kilns (CDK), which have reported cost savings and potential improvements in product dried quality (Wellons 2018). Timber stacks dried in a CDK pass through the kiln in opposite directions on two tracks so that heat coming off the dry timber preheats the green timber packs, and the moisture coming off the green timber conditions the dry timber. This energy efficient process happens at both ends. Considerable thermal energy efficiencies of approximately $30 \%$ are achieved with CDK kilns alongside a number of other reported benefits (Mahild 2017; Leggate et al. 2020).

The drying quality of various timber species have been investigated. Kliger et al. (2005) studied various distortion parameters, i.e., twist, bow and spring, of Norway spruce studs that were dried using the high-temperature method (HT) at a temperature of $115^{\circ} \mathrm{C}$ and the low-temperature method (LT) at a temperature of $70^{\circ} \mathrm{C}$. They found that the HTdried timber had significantly lower distortion values than the LT-dried timber. Stress formation, moisture gradients, and timber distortion as well as the moisture content distribution within various sections of the timber stack and the internal checking and collapse development were assessed on Eucalyptus delegatensis boards dried in a greenhouse solar kiln (Phonetip et al. 2019). They found that all sample boards were within the acceptable limits for cupping, spring, and bow. However, the amount of twist in three out of twelve sample boards was above the acceptable limit in accordance with AS/NZS standard 4787 (2001). For internal checking, collapse, and residual stress criteria, the boards were graded as Class " $\mathrm{C}$ " (class A is the highest grade and D is the lowest) according to AS/NZS standard 4787 (2001). Yuniarti et al. (2015) investigated the moisture distribution/ profile and defect development in E. saligna during intermittent drying. The defects observed were checks (surface and end) and distortions (bow, spring, twist, and cupping) at various moisture levels. They found that the development of surface checks, end checks, bow, spring, and twist in some affected boards started when the average moisture content of the boards was still greater than $50 \%$.

Frühwald (2007) investigated the effects of restraining during pre-steaming, drying, and steaming on the short-term twist reduction of Norway spruce and found that the restrained specimens sawn close to the pith experienced reduced twist. The twist depended 
on the distance of the boards from the pith. Restrained specimens sawn close to the pith experienced reduced twist. The drying temperature did not significantly influence twist during moisture cycling. Johansson and Kliger (2007) studied the influence of material characteristics, e.g., average distance from the pith, grain angle, amount of juvenile wood, ring width, compression, knots, cracks, wane, density, and modulus of elasticity, on the warp in Norway spruce timber. The grain angle and annual ring curvature were found to attribute to $73 \%$ of the variation in twist. Bow and crook (spring) were not possible to explain with statistical models. Rabidin et al. (2017) found that a radio frequency-vacuum drying (RFV) drying system reduced drying time by $50 \%$ compared to conventional kiln drying and achieved uniform MC between and within the boards. They found negligible cupping, bowing, and spring as well as no twist for $30 \mathrm{~mm}$ and $50 \mathrm{~mm}$ thick kekatong (Cynometra spp.) timber. Cown et al. (1996) studied various factors, e.g., raw material $(\log s)$, secondary processing technology (sawing pattern, drying method, and the influence of planing), product (lumber dimensions), and standards (grading rules), that influence the distortion of radiata pine (Pinus radiata D. Don). The strong propensity for lumber from small diameter and physiologically young logs to degrade was confirmed, and over $90 \%$ of the problem was related to twist rather than spring or bow. In the worst cases, i.e., in small juvenile logs, with a low temperature drying, and no planning, up to $80 \%$ of the boards were categorized as "rejects".

Carnavas and McNaught (1991) examined the influence of various methods of plasticisation and post drying steaming on the distortion and stability of high temperature drying slash pine. Although no considerable difference in the distortion was reported with pre- or post-steaming, the results did show the importance of moisture content in influencing the dimensional stability of the timber during drying. They recommended to reduce the moisture content variation within particular kiln charges and between kiln charges and to apply steaming close to a temperature of $100{ }^{\circ} \mathrm{C}$ for approximately $2 \mathrm{~h}$ per $25 \mathrm{~mm}$ of thickness following drying (Carnavas and McNaught 1991). They also concluded that the steaming time may be critical for the prevention of internal checking and the restraint weight should not be removed from the stacks until the timber has cooled following steaming.

$\mathrm{Wu}$ and Smith (1997) dried 192 pieces of matched southern pine lumber in two separate charges at two different drying schedules: elevated temperature (ET) and hightemperature (HT). The ET schedule consisted of a dry bulb temperature ramped from 170 ${ }^{\circ} \mathrm{F}\left(76.7^{\circ} \mathrm{C}\right)$ to $200{ }^{\circ} \mathrm{F}\left(93.3{ }^{\circ} \mathrm{C}\right)$ over $52 \mathrm{~h}$ at a constant wet bulb temperature of $150{ }^{\circ} \mathrm{F}$ $\left(65.6{ }^{\circ} \mathrm{C}\right)$. The HT schedule included a dry bulb temperature of $230{ }^{\circ} \mathrm{F}\left(110^{\circ} \mathrm{C}\right)$ and a wet bulb temperature of $180^{\circ} \mathrm{F}\left(82.2^{\circ} \mathrm{C}\right)$. It was found that boards dried with the ET schedule had a considerably higher crook than the boards from the HT schedule. The bow and twist from the ET schedule were also higher, but no considerable difference was found between the two schedules. The crook was shown to co-vary with the largest knot area. Twist covaried considerably with the specific gravity, juvenile wood content, and number of rings per inch for the test lumber.

The reported effect of the drying temperature on various wood mechanical properties, e.g., the modulus of elasticity (MOE) and modulus of rupture (MOR), were conflicting between researchers. While some pine studies reported that high temperature drying resulted in no considerable changes in the mechanical properties (Koch 1971; Yao and Taylor 1979; Taylor and Mitchell 1987; Thiam et al. 2002), others reported considerable reductions (Hartley 1975; Taylor and Mitchell 1987; Frühwald 2007). In addition, some research reported a reduction in the MOR but no change in MOE via high 
temperature drying (Bekhta and Niemz 2003; Herrera-Díaz et al. 2017).

Recently, Leggate et al. (2020) investigated the differences between continuous drying and conventional high and low temperature drying schedules on the permeability, wettability, gluability, and treatability of southern pine timber from Queensland. Their results showed no considerable differences between the drying schedules for gas permeability. However, the high temperature drying resulted in considerably lower liquid permeability compared to low temperature drying. For earlywood after surface machining, continuous drying resulted in the greatest wettability, whereas for latewood after surface machining, low temperature drying produced the greatest wettability. Earlywood had greater wettability compared to latewood. Continuous drying resulted in better gluability and treatability compared to conventional drying schedules. However, to the best knowledge of the authors, there is no published research comparing the drying quality between continuous drying and high temperature drying technology for Australian southern pine timber. This study aims to investigate the impact of a relatively new continuous drying kiln (CDK) technology in Australia on the drying quality of a southern pine plantation timber in Queensland compared to the current ultra-high temperature (HTD) batch drying process. The drying quality investigated in this study includes the final moisture content variation, moisture gradient, residual drying stress, distortion of different types, e.g., bow, cup, twist and spring, as well as surface and internal checking, in accordance with various Australian/New Zealand standard test methods, and resin bleed out.

\section{EXPERIMENTAL}

\section{Sample Preparation and Drying}

A pack of backsawn, unseasoned (average moisture content (MC) of $84 \%$ ), southern pine timber (Pinus elliottii (PEE), Pinus caribaea $(\mathrm{PCH})$, and $\mathrm{PEE} \times \mathrm{PCH}$, i.e., the hybrid between these two species) with nominal dimensions of $100 \mathrm{~mm} \times 38 \mathrm{~mm} \times$ $6000 \mathrm{~mm}$ was obtained from a commercial sawmill in Queensland, Australia. The boards were then assessed to locate sections of material containing minimal visual defects, e.g., knots, splits, resin pockets, and test specimens were cut from the parent boards with nominal dimensions of $100 \mathrm{~mm} \times 38 \mathrm{~mm} \times 900 \mathrm{~mm}$; the cut test specimens were then randomly allocated to the two drying conditions. The details of the sample preparation and allocation was provided in the authors previous article (Leggate et al. 2020). The number of boards assessed after drying were 29 and 33 for continuous drying and high temperature drying, respectively. These samples were then end sealed using a polyurethane sealant called Sikaflex manufactured by Sika Australia, and then weighed, wrapped, and then stored in a cool room set to $4{ }^{\circ} \mathrm{C}$ until drying was ready to commence.

Both the high temperature drying and continuous drying were undertaken in an experimental kiln with a drying chamber of $1.2 \mathrm{~m} \times 1 \mathrm{~m} \times 0.44 \mathrm{~m}$ (length $\times$ width $\times$ height). Figure 1 shows the experimental kiln with a kiln charge and instrumentations. The schedules were provided by an Australian producer for the HTD schedule and from a CDK manufacturing company for the continuous drying schedule. For the high temperature drying, the schedule was a typical high temperature drying schedule used for drying softwood structural-grade sawn timber in Australia. Set points ranged from 25 to $180{ }^{\circ} \mathrm{C}$ $\mathrm{DB}, 7.3 \%$ to $82 \%$ relative humidity (RH), and 3 to $7 \mathrm{~m} / \mathrm{s}$ air flow, depending on the stage of the drying schedule. The total drying time was 477 min $(8 \mathrm{~h})$. Continuous drying was 
undertaken with a schedule representative of typical drying conditions targeted with continuous drying kilns for structural-grade softwood timber. Set points ranged from 25 to $115{ }^{\circ} \mathrm{C} \mathrm{DB}, 34 \%$ to $100 \% \mathrm{RH}, 2.3 \%$ to $23 \% \mathrm{EMC}$, and 3 to $5.5 \mathrm{~m} / \mathrm{s}$ air flow, depending on the stage of the drying schedule. The total drying time was $36 \mathrm{~h}$. Due to confidentiality and intellectual property, the names of the companies and the full drying schedules have been excluded.

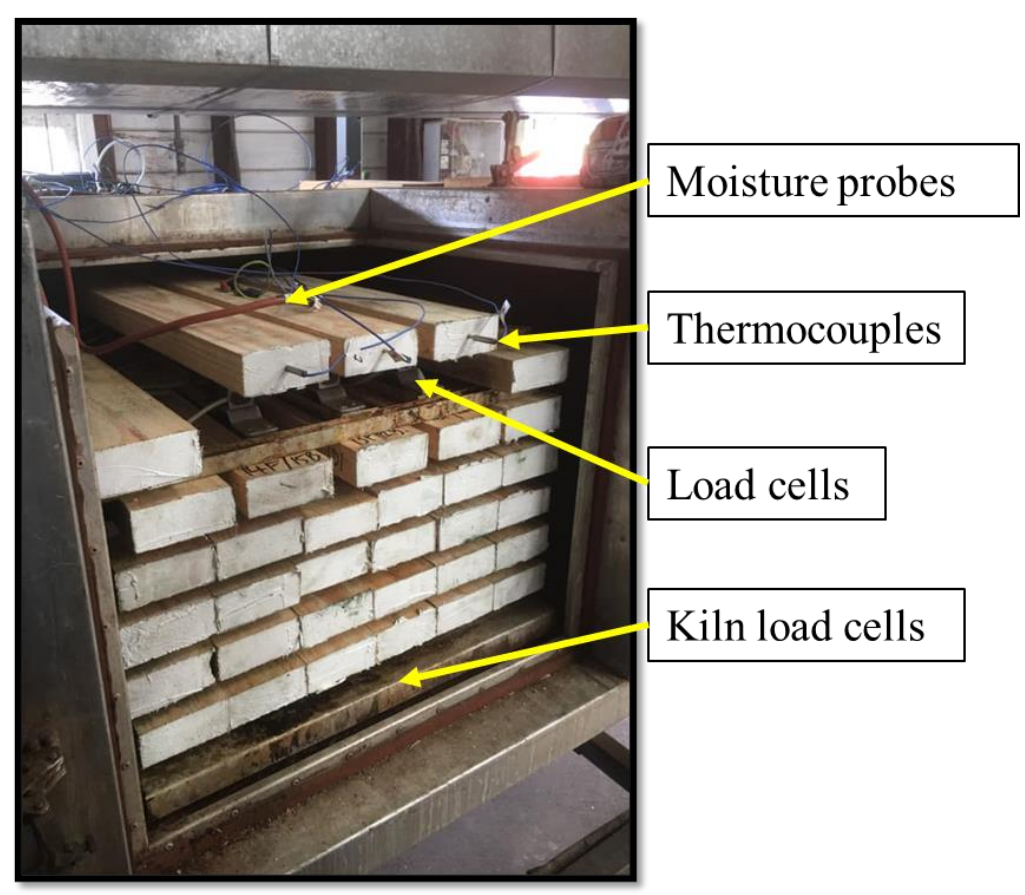

Fig. 1. Stickered timber charge with load cells, thermocouples and moisture probes installed in the experimental kiln at Salisbury Research Facility, Department of Agriculture and Fisheries, Queensland, Australia

\section{Moisture Content (MC)}

The MC was determined using the oven-dry method in accordance with AS/NZS 1080.1 (2012) from a $25 \mathrm{~mm}$ cross section. The MC of the samples was calculated according to Eq. 1,

$$
M C=\frac{M_{i}-M_{o}}{M_{o}} \times 100
$$

where $\mathrm{MC}$ is the percentage moisture content of test piece, $M_{i}$ is the initial mass of test piece $(\mathrm{kg})$, and $M_{o}$ is the oven-dry mass of test piece $(\mathrm{kg})$. The oven dry mass of the test pieces was determined after the samples were dried in a laboratory oven at a temperature of $103{ }^{\circ} \mathrm{C} \pm 2{ }^{\circ} \mathrm{C}$ for $24 \mathrm{~h}$ and until the weight of the sample had stabilized.

\section{Moisture Gradient}

The moisture gradient after drying was measured in accordance with AS/NZS 1080.1 (2012), by taking a sample with a cross section of $25 \mathrm{~mm}$ and dividing the sample into three zones (as shown in Fig. 2). Using a small bandsaw, the outer 1/4 thickness (T/4) sections of the MC gradient samples were cut from both faces to obtain the case MC. The remaining section in the middle (T/2) was further sawn to remove both outer ends of $1 / 4$ thickness to obtain a core MC (as shown in Fig. 2). 


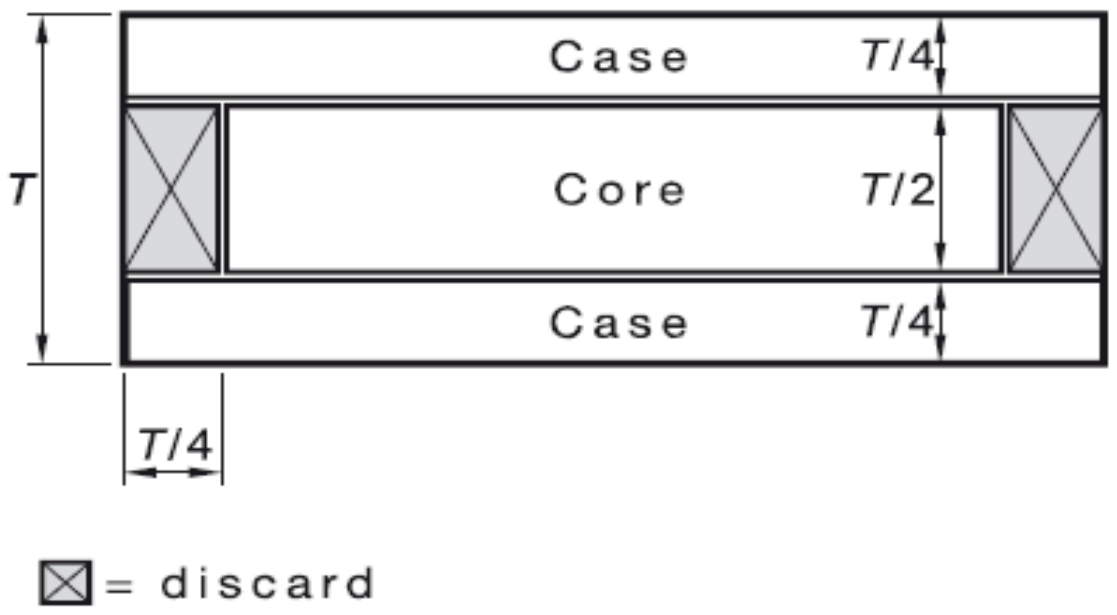

Fig. 2. Moisture content gradient sampling procedure

Using the oven-dry MC procedure already discussed, the MC of each section (case and core) was measured and calculated using Eq. 1. The MC gradient of each test piece was calculated according to Eq. 2,

$$
M C G=M C_{\text {core }}-\frac{M C_{\text {case } 1}+M C_{\text {case } 2}}{2}
$$

where $\mathrm{MCG}$ is the $\mathrm{MC}$ gradient, $\mathrm{MC}_{\text {core }}$ is the $\mathrm{MC}$ of the internal core section, and $\mathrm{MC}_{\text {case } 1}$ and $\mathrm{MC}_{\text {case } 2}$ are the MCs of the external 'top case' and 'bottom case' sections, respectively.

\section{Residual Drying Stress}

Sectional variation in the MC and the associated shrinkage results in tension and compression stress during drying. When the drying was complete, a $50 \mathrm{~mm}$ cross section was removed (adjacent to the MC sample location) and used to quantify residual drying stress in accordance with AS/NZS standard 4787 (2001). The samples were free of characteristics, e.g., knots, severe sloping grain, and reaction wood. The width $(W)$ of each drying stress sample was measured using Vernier calipers. Samples were cut through the center using a small bandsaw in the orientation shown in Fig. 3.

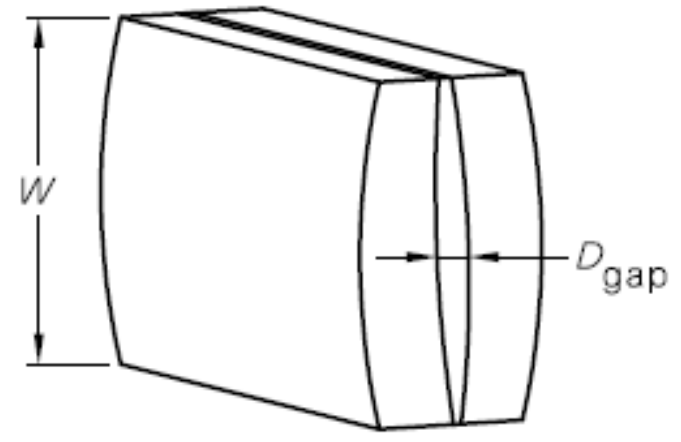

Fig. 3. Measuring the residual drying stress

Within 5 min after ripping, the two halves were reassembled such that the concave faces oppose each other (as shown in Fig. 3). The freshly cut faces were then re-aligned 
and the largest gap between them measured ( $\left.D_{\text {gap }}\right)$ (Redman 2017). The degree of drying stress $\left(D_{\text {stress }}\right)$ is the ratio of the gap width and section width expressed as a percentage, as shown in Eq. 3,

$$
D_{\text {stress }}=\left(\frac{D_{g a p}}{W}\right) \times 100
$$

\section{Distortion or Warp}

Distortion or warp are changes in the shape of a piece of timber. Distortion includes cup, bow, twist, spring (crook), and diamonding, or a combination of some or all these factors. Each board was graded for distortion, i.e., twist, spring, bow, and cup, in accordance with AS/NZS standard 2796.3 (1999).

\section{Checking}

When drying stresses exceed the tension strength of wood perpendicular to the grain, the timber fibres separate, which is commonly referred to as checking. When the kiln drying process was complete, each board was assessed for surface checking (on both wide faces) and internal checking in accordance with AS/NZS standard 4787 (2001). The total length of the surface checking was measured in a section of the board free of defects, e.g., knots and resin streaks, on both faces and the largest amount of checking was recorded. The percentage of surface check affected material was calculated by adding the total length of board affected and dividing by the total board length. Internal checks were exposed by docking a selected sample board into $300 \mathrm{~mm}$ lengths. Each docked end was inspected, and the presence or absence of internal checking was recorded and measured using a vernier caliper; a measurement was taken for each individual check detected.

\section{Resin}

A clean aluminum sheet was placed on top of the load cell table to collect resin that came out of the timber. A hollow steel section was mounted at the back of the stack to monitor if any resin came out and followed the direction of the air flow and deposited on the steel section.

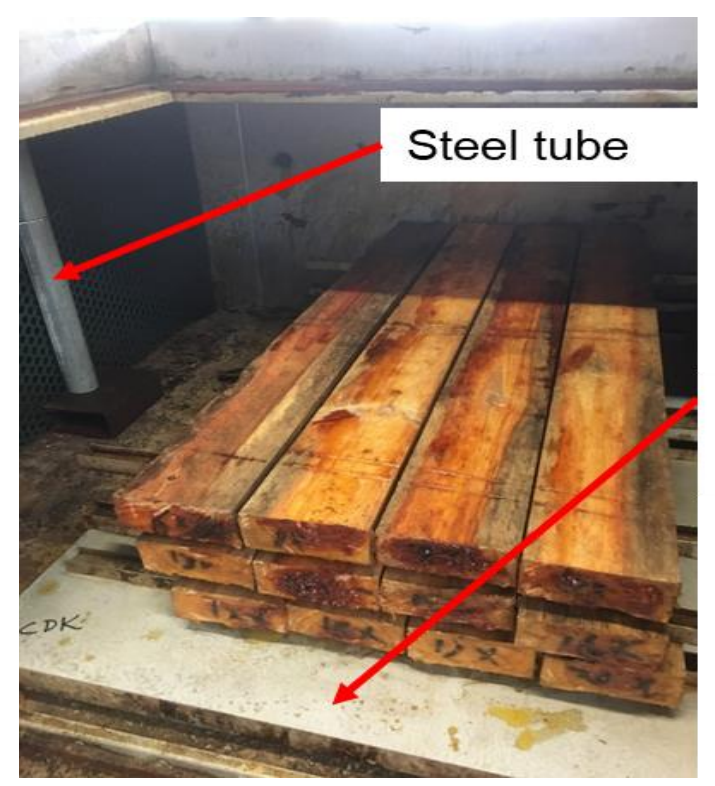

Aluminium sheet

Fig. 4. The experimental setup for resin accumulation 


\section{Dynamic Modulus of Elasticity (MOE)}

Non-destructive assessment methods for estimating the mechanical descriptor, e.g., the modulus of elasticity and shear moduli, were used to allow for these properties to be quantified from the dried boards while still allowing for further test samples to be taken after testing. The test consists of the sample being freely supported using elastic restraints and impacted on one side, with a microphone on the other side to detect the acoustic response (Fig. 5). Using specific signal processing techniques and a commercially available system $\left(\mathrm{BING}^{\odot}\right)$, the acquired signal was then analyzed to obtain the natural frequencies for determining the MOE.

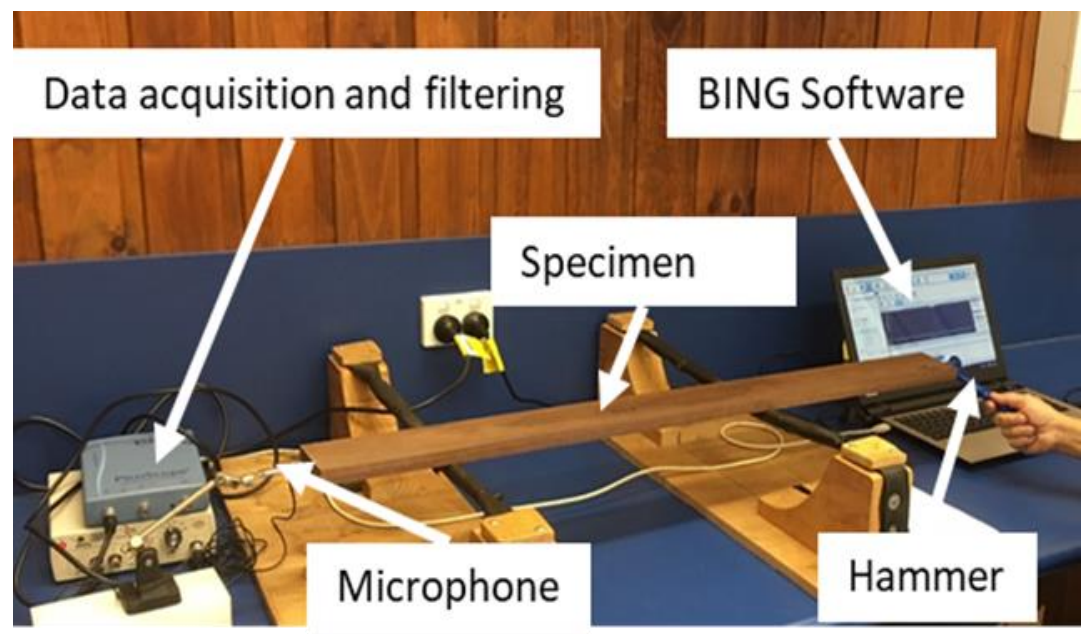

Fig. 5. Setup used for testing the dried boards with the $\mathrm{BING}^{\odot}$ system

\section{Statistical Analysis}

Statistical analysis was performed using the open-source statistical package RStudio (version 1.3.1058, RStudio, Boston, MA). Both analysis of variance (ANOVA) and pairwise comparisons using Fisher's protected least significant difference (LSD) test were used.

\section{RESULTS AND DISCUSSION}

\section{Final Moisture Content (MC) and MC Gradient}

Figure 6 shows the final moisture content for both the HTD and CDK samples. The HTD showed a greater range in MC, which deviated greatly from the target MC, when compared with CDK. This indicated that some boards were over dried, and some were under dried during the high-temperature drying process. The CDK process had a fewer number of over-dried and under-dried boards compared to HTD. This was expected for continuous drying due to the longer and better conditioning phase after the primary drying phase. Although the mean MC for both the HTD and CDK were $7.98 \%$ and $7.23 \%$, respectively, the variation was wider in the HTD process compared to CDK, with COV values of the MC of $48 \%$ for HTD and $6 \%$ for CDK. These results show the final MC just after drying is completed, where the target mean moisture content for both drying regimes was similar. The tighter moisture distribution, i.e., lower standard deviation, for continuous drying has been reported earlier in various reports (USNR 2019). 


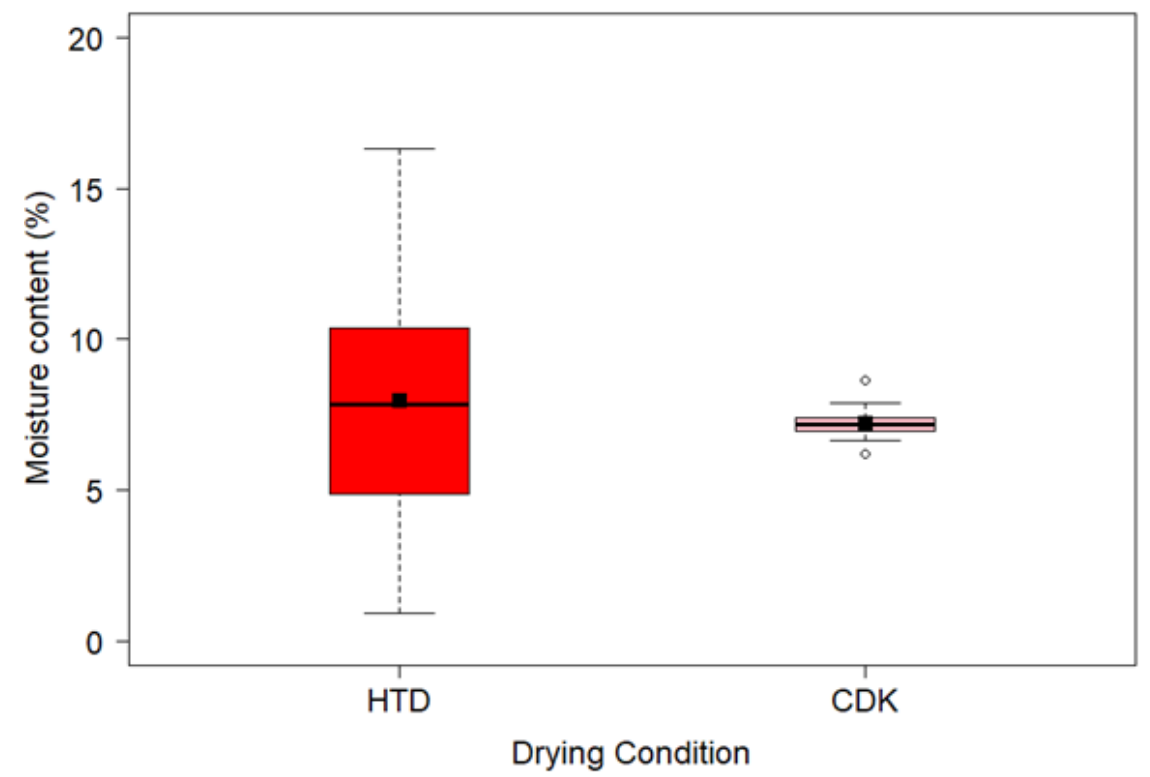

Fig. 6. Moisture content of HTD and CDK dried boards

Table 1. Variation in the Moisture Content (MC) Gradient Data

\begin{tabular}{|c|c|c|}
\hline Drying Condition/Dispersion & HTD & CDK \\
\hline Minimum & 0.93 & 6.21 \\
\hline Maximum & 16.32 & 8.66 \\
\hline Mean & $7.98 \mathrm{a}$ & $7.23 \mathrm{a}$ \\
\hline Standard deviation & 3.83 & 0.45 \\
\hline COV (\%) & 48.07 & 6.24 \\
\hline Note: Means followed by the same letter are not significantly different ( $p$-value equals 0.05) \\
\hline
\end{tabular}

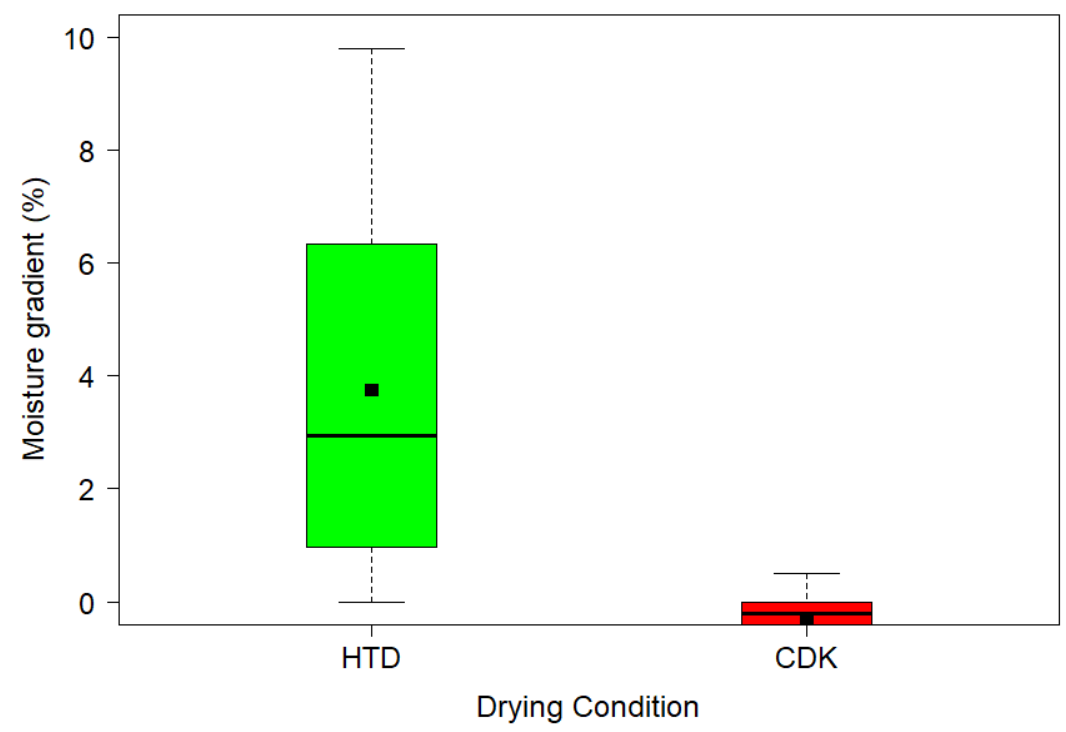

Fig. 7. MC gradient of the HTD and CDK dried boards

Figure 7 shows the boxplots for the MC gradient of the CDK and HTD dried boards. The percentage difference between the core and case moisture content, referred to as the 
moisture gradient, was much tighter in CDK, as expected. This is because of the longer conditioning phase after the primary drying stage in the CDK schedule, which is a major advantage of CDK. Ward and Simpson (1997) stated that the rejection of boards due to an uneven MC and MC gradient can cause a considerable reduction in recovery and profit. CDK can significantly reduce these rejections.

\section{Distortion}

Figure 8 shows the boxplots for the various types of distortion. The boxplots for distortion show that the boards dried with continuous drying schedules resulted in slightly lower median values for bow and spring and similar cup and twist median values when compared to high temperature dried boards. However, the differences were not statistically significant.
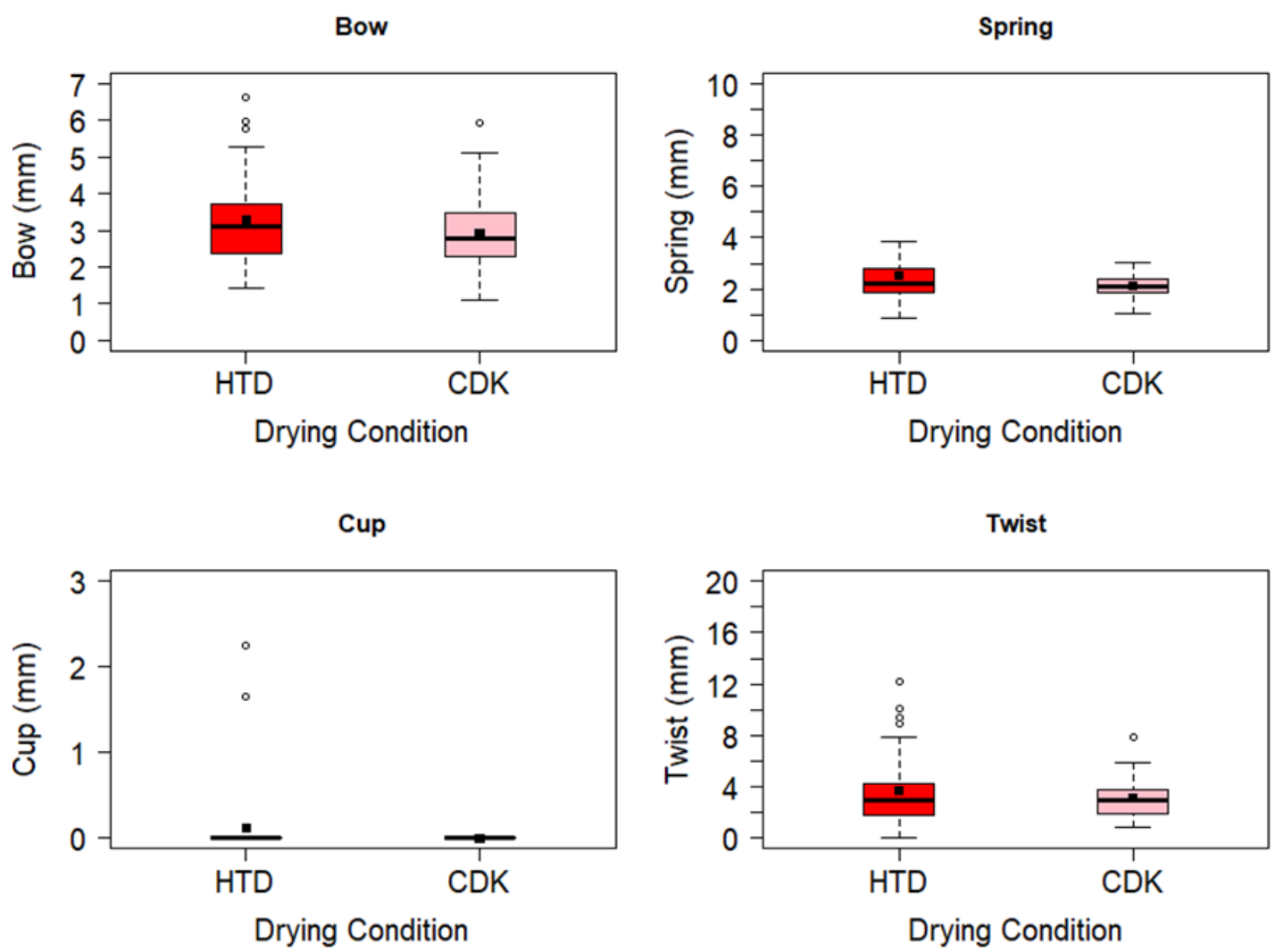

Fig. 8. Distortions of the HTD and CDK dried boards: a) bow; b) spring; c) cup; and d) twist

Table 2 shows the variation in the distortion data. The mean, maximum, and COV of all these distortion properties were smaller for CDK compared to HTD. For example, the maximum twist was $12.25 \mathrm{~mm}$ for HTD and $7.82 \mathrm{~mm}$ for CDK and the max spring for HTD was $10.62 \mathrm{~mm}$, whereas it was only $3.05 \mathrm{~mm}$ for CDK. The coefficient of variation was also smaller in the continuous drying process compared to the high temperature drying process for all four types of distortion. No cupping was observed in CDK and only two boards cupped in HTD. Cown et al. (1996) also mentioned that twist was a major problem in radiata pine drying compared to other types of drying degradation. Phonetip et al. (2019) also found higher twist compared to other types of distortion in a study on the solar drying of Eucalyptus delegatensis. They found three out of twelve boards were twisted above the 
acceptable limit, whereas cupping, spring, and bow were within acceptable limits. In contrast Rabidin et al. (2017) found negligible cupping, bow, and spring as well as no twist for $30 \mathrm{~mm}$ and $50 \mathrm{~mm}$ thick kekatong (Cynometra spp.) timber.

Table 2. Variation in the Distortion Data

\begin{tabular}{|c|c|c|c|c|c|c|c|c|}
\hline & \multicolumn{2}{|c|}{ Bow $(\mathrm{mm})$} & \multicolumn{2}{c|}{ Cup (mm) } & \multicolumn{2}{c|}{ Twist (mm) } & \multicolumn{2}{c|}{ Spring (mm) } \\
\hline \multirow{2}{*}{ Drying condition } & HTD & CDK & HTD & CDK & HTD & CDK & HTD & CDK \\
\hline Minimum & 1.44 & 1.10 & 0.00 & 0.00 & 0.00 & 0.90 & 0.88 & 1.06 \\
\hline Maximum & 6.60 & 5.92 & 2.25 & 0.00 & 12.25 & 7.82 & 10.62 & 3.05 \\
\hline Mean & $3.30 \mathrm{a}$ & $2.91 \mathrm{a}$ & $0.12 \mathrm{a}$ & $0.00 \mathrm{a}$ & $3.75 \mathrm{a}$ & $3.15 \mathrm{a}$ & $2.55 \mathrm{a}$ & $2.14 \mathrm{a}$ \\
\hline Standard deviation & 1.27 & 1.02 & 0.48 & 0.00 & 3.07 & 1.64 & 1.63 & 0.40 \\
\hline COV (\%) & 38.55 & 35.04 & 400 & 0.00 & 81.91 & 52.09 & 63.93 & 18.82 \\
\hline Not & & & & & & & & \\
\hline
\end{tabular}

Note: Means followed by the same letter for bow, cup, twist, and spring are not significantly different ( $p$-value equals 0.05$)$

The cupping results also conformed with the findings of Yuniarti et al. (2015). They noticed no cupping in intermittent dried boards of E. saligna. However, they attributed this low cupping to the intermittent drying method, which has the potential to minimize the cupping of E. saligna wood. Johansson and Ormarsson (2009) reported that distortion is highly influenced by numerous parameters, e.g., spiral grain angle, modulus of elasticity, shrinkage, growth stresses, and sawing pattern, which were not investigated in this study.

Vasileios et al. (2017) found that warping defects, i.e., cup, spiral, warp, bow, and crook, ranged from $0.28 \mathrm{~cm}$ up to $11.91 \mathrm{~cm}$ for $3 \mathrm{~m}$ long boards of Greek Macedonian fir (Abies borisii-regis). They found lower warping (distortion) when using the slower kiln drying method.

It should be noted that the distortion measurements in this study were conducted under unrestricted conditions, i.e., without any dead load on top of the pack. Unrestricted drying leads to very high levels of distortion (Mishiro and Booker 1988; Cown et al. 1996). Therefore, the results may not represent the actual quantitative values obtained in industrial drying practice. There is insufficient basis to determine whether the boards meet the industry or standard requirement for this study. However, this provides a comparative study between high temperature and CDK, as both were dried under the same conditions. Further research is needed to assess the performance and comparative effects on separate charges dried using the two presented schedules in a full-scale trial, involving longer board lengths, which would involve boards being placed under weight restraint; this is expected to reduce losses in distortion-prone materials for both drying conditions. Growth related distortion, e.g., from growth stresses, was not considered for the green boards, i.e., no green measurements were conducted. The authors have conducted a separate study performed on longer length boards dried in a semi-industrial scale kiln under restraint weight to represent industrial conditions which will be reported in following articles.

\section{Residual Drying Stress}

Figure 9 shows that the residual drying stress was also much smaller in the CDK process compared to the HTD process. The mean stress was smaller for continuous drying; however, the COV for CDK was $110 \%$. This is because the drying stress data was not 
normally distributed. As can be seen in the histogram, the majority of the boards had close to zero drying stress (as shown in Fig. 10). This is because of the longer reconditioning time, which is one of the reported benefits of continuous drying. The least significant difference (LSD) test showed that the drying stress in high temperature drying was significantly higher ( $p$-value less than 0.005).

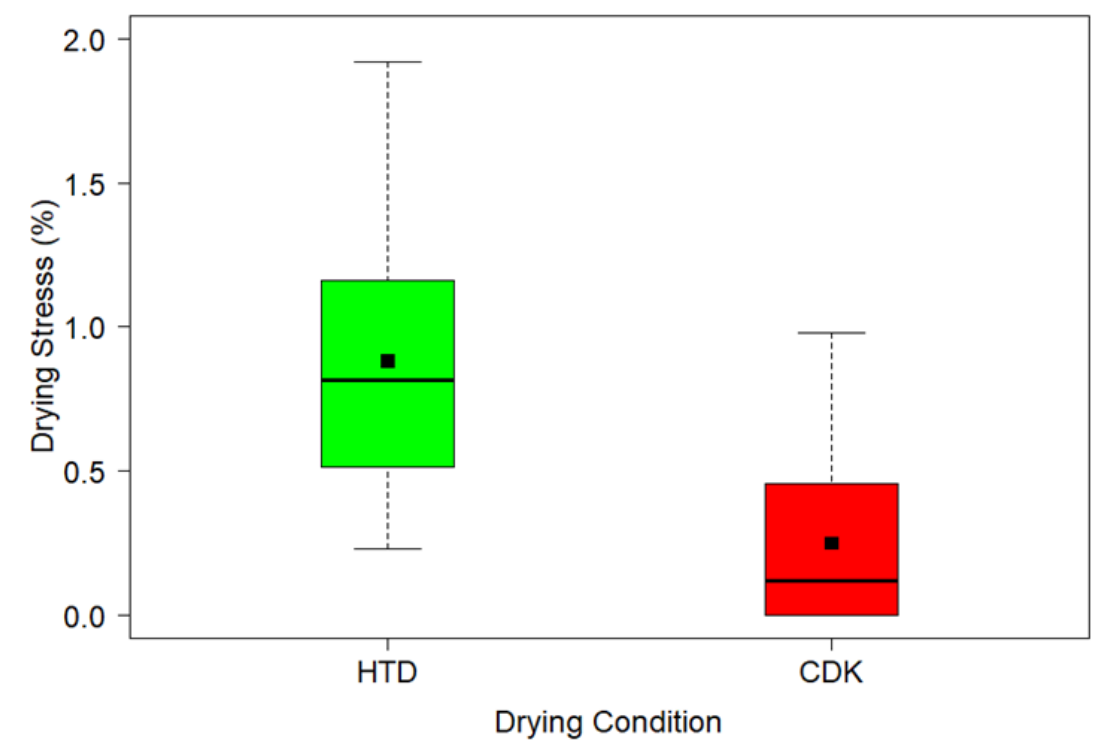

Fig. 9. Drying stress for the HTD and CDK dried boards

Other alternative drying methods, e.g., radio frequency-vacuum drying (RVF), could also improve the number of stress-free boards (Rabidin et al. 2017).
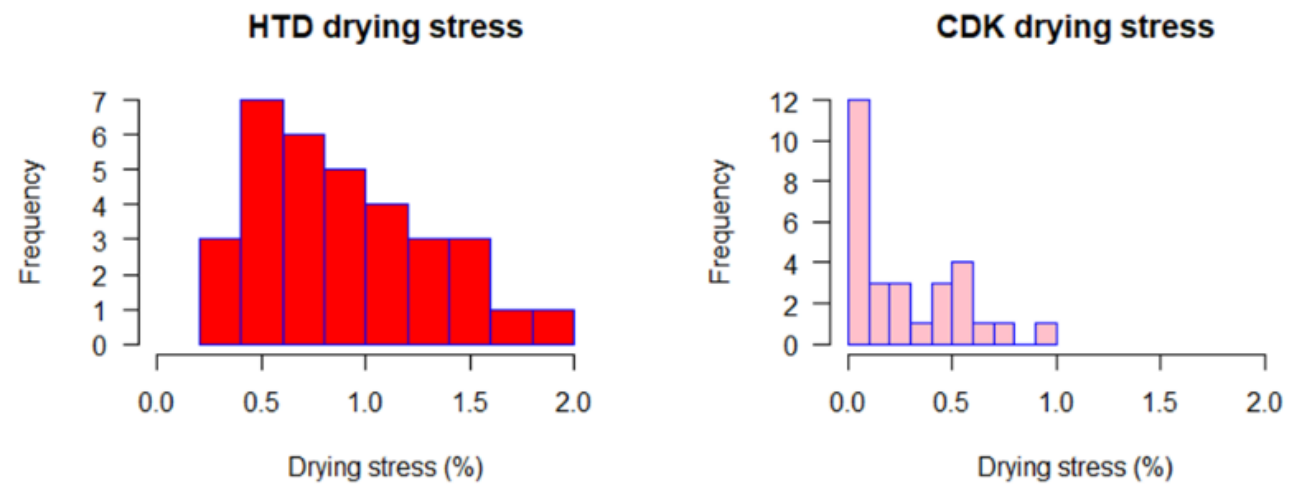

Fig. 10. Histogram of the drying stress for the HTD and CDK dried boards

\section{Surface and Internal Checking}

Interestingly, less surface checking was observed in HTD than CDK (Fig 11). The reason behind this is thought to be that the surface checking was difficult to observe, as they may have closed in the later stage of drying due to the higher internal stress in HTD. This interpretation is further reinforced by the amount of internal checking recorded and shown in Table 4; the HTD boards recorded approximately 5 times the amount of internal checking compared to the CDK dried boards. The surface checking was significantly higher in CDK than in HTD ( $p$-value equals 0.00538). 


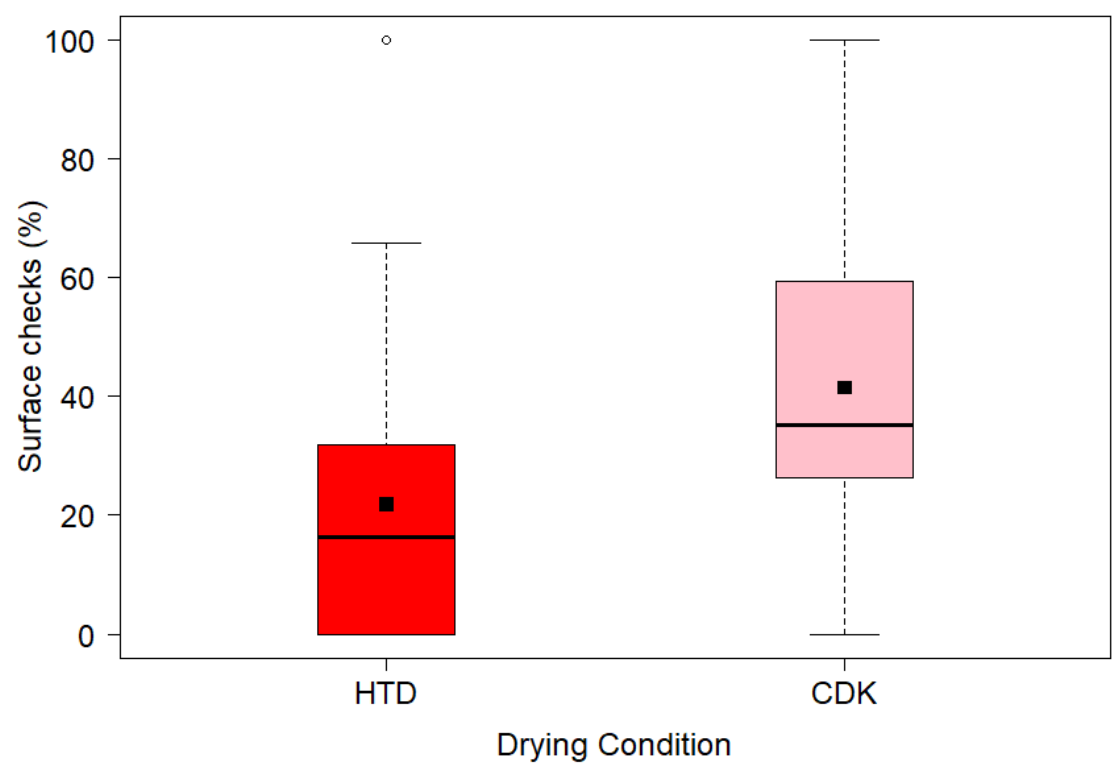

Fig. 11. Surface checking for the HTD and CDK dried boards

Table 3. Variation in the Surface Checking

\begin{tabular}{|c|c|c|}
\hline Drying Condition/Dispersion & HTD (\%) & CDK (\%) \\
\hline Minimum & 0.00 & 0.00 \\
\hline Maximum & 100.00 & 100.00 \\
\hline Mean & $21.85 \mathrm{a}$ & $41.58 \mathrm{~b}$ \\
\hline Standard deviation & 25.57 & 28.23 \\
\hline COV (\%) & 117.05 & 67.89 \\
\hline Note: Means followed by the same letter are not significantly different ( $p$-value equals 0.05$)$ \\
\hline
\end{tabular}

Internal checking was significantly higher in HTD; $51 \%$ of the boards had internal checking while only $17 \%$ of the boards had internal checks in CDK.

During the beginning of the drying process, the casing of the board (external shell) experiences tension and the core experiences compression due to moisture loss and shrinkage near the surface. This situation is reversed in the latter stage, as the case is set, and the core starts to shrink, which results in compression in the case and tension in core. The surface checking can close in the later stage of drying and can be hard to see without planing (Simpson 1999).

Table 4. Variation in the Internal Checking

\begin{tabular}{|c|c|c|}
\hline Drying Condition & Total Internal Checks $(\mathrm{mm})$ & Boards Affected (\%) \\
\hline HTD & $331.43 \mathrm{a}$ & 51 \\
\hline CDK & $72.08 \mathrm{~b}$ & 17 \\
\hline \multicolumn{2}{|c|}{ Note: Means followed by the same letter are not significantly different ( $p$-value equals 0.05$)$} \\
\hline
\end{tabular}

\section{Resin}

The total resin accumulated in the steel hollow sections, aluminum plates, and stickers weighed $125 \mathrm{~g}$ and $17.3 \mathrm{~g}$ for HTD and CDK, respectively. Therefore, HTD resulted in more than 7 times the resin accumulation in the kiln compared to CDK. 
Approximately $60 \%$ of the resin was accumulated on the aluminum sheet underneath the drying stack, the stickers accumulated approximately $30 \%$, and the steel tube accumulated approximately $10 \%$ for CDK. For HTD, approximately $70 \%$ of the resin was accumulated on the aluminum sheet underneath the drying stack and the aluminum stickers accumulated approximately $30 \%$ (Fig.12). The higher resin exudation from the HTD process can be most likely attributed to the higher temperature, which liquefies the resin and possibly also results in a greater pressure gradient flow from the inner part of the board toward the surface. Note that this experiment was done with high-resin content boards taken near the pith of the tree.

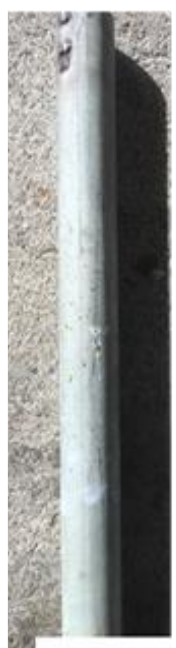

CDK
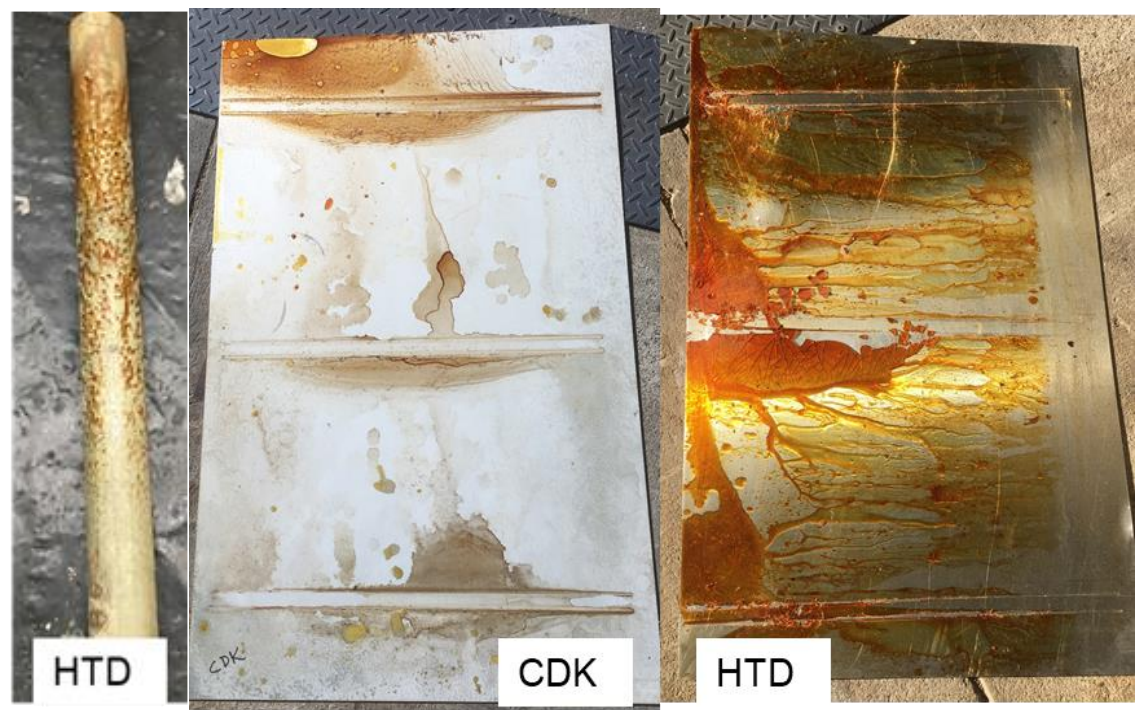

Fig. 12. Resin accumulation on the back steel tube and bottom surface of the kiln for HTD and CDK dried boards

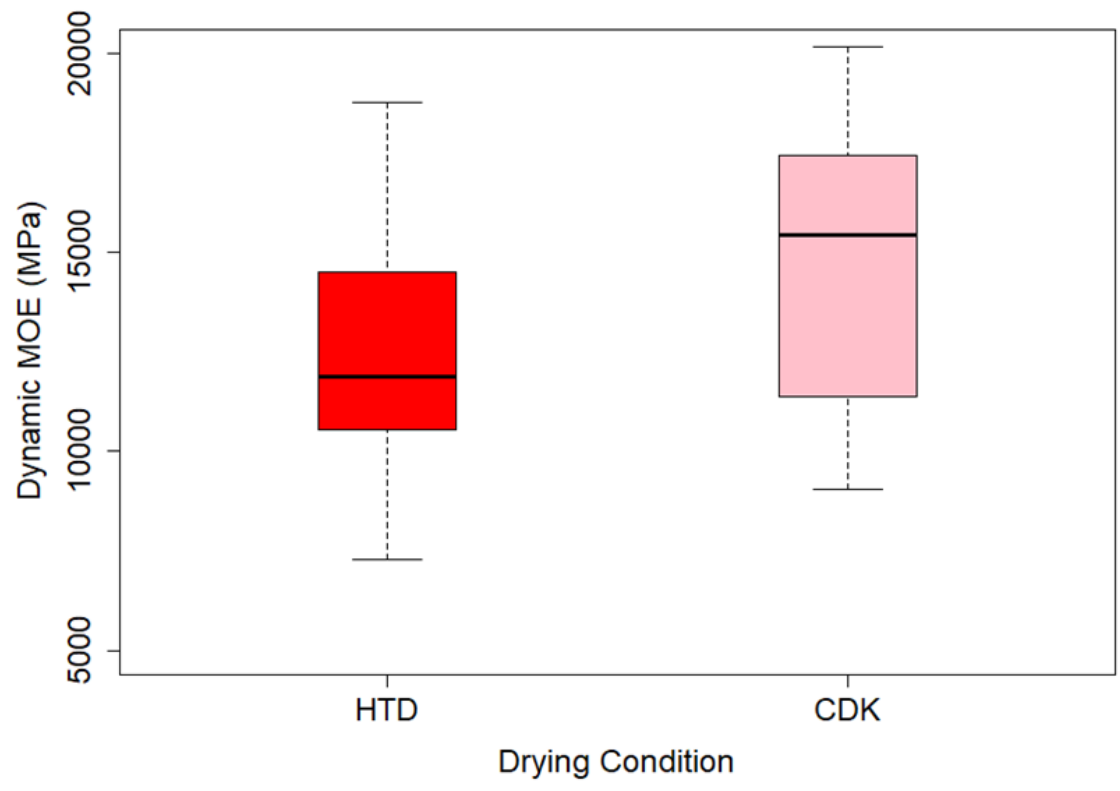

Fig. 13. The MOE of the HTD and CDK dried boards 


\section{Dynamic Modulus of Elasticity (MOE)}

Overall, there seemed to be little difference between the two drying conditions in terms of the mechanical properties after drying, with CDK having a slightly higher mean MOE result than the conventional HTD dried boards (Fig. 13). This could be due in part to the magnitude of internal checking discussed above, noting an increase in internal checking for the HTD boards, which is most likely due to the higher internal stresses the boards were exposed to. While the MOE for the CDK boards on average sits above the HTD boards, the results yielded a higher variation in the MOE for the CDK compared to the HTD boards. There were no significant differences in the MOE between the CDK and HTD processes (ANOVA $p$-value equals 0.162). Cai and Oliveira (2008) also reported statistically insignificant reductions in the MOE and MOR from high temperature drying when compared with low to moderate drying temperatures for spruce and pine. Terziev and Daniel (2002) also reported that there was no critical reduction in the impact bending strength, hardness, and MOE of the dried untreated wood regardless of the drying method in Scots pine timber.

Table 5. Variation in the Modulus of Elasticity (MOE) Data

\begin{tabular}{|c|c|c|}
\hline Drying Condition/Dispersion & HTD (MPa) & CDK (MPa) \\
\hline Minimum & 7280 & 9054 \\
\hline Maximum & 21996 & 20176 \\
\hline Mean & $12846 \mathrm{a}$ & $14451 \mathrm{a}$ \\
\hline Standard deviation & 3589 & 3561 \\
\hline COV (\%) & 27.9 & 24.6 \\
\hline \multicolumn{2}{|c|}{ Note: Means followed by the same letter are not significantly different ( $p$-value equals 0.05) } \\
\hline
\end{tabular}

\section{CONCLUSIONS}

1. The continuous drying kiln $(\mathrm{CDK})$ process yielded significantly less under-dried and over-dried boards with a smaller variation in moisture content compared to the hightemperature drying (HTD) process. The moisture distribution was more even in CDK than HTD. This moisture gradient improvement was a significant benefit of CDK, which reduced the subsequent loss of rejected product.

2. The boards dried with CDK schedules resulted in slightly lower median values for bow and spring and similar cup and twist median values compared to HTD boards. Although the drying was unrestricted (no weight loading applied) for both HTD and CDK, the comparison was valid and shows that there was no significant difference in distortion values.

3. The drying stress was significantly lower ( $p$-value less than 0.0005) in CDK compared to HTD.

4. Resin bleed out on the bottom surface of the kiln was found to be higher for HTD compared to CDK.

5. Surface checking was significantly higher in the CDK boards when compared to the HTD boards. However, the internal checking in the HTD boards was 5 times the amount of internal checking recorded in CDK, with greater than $51 \%$ of the HTD boards recording some form of internal checking and only $17 \%$ of the CDK boards 
showing any internal checking.

6. The modulus of elasticity (MOE) was not significantly affected by the two drying conditions, but a slightly higher MOE on average was measured in the CDK boards compared to the HTD boards. In addition, the CDK dried boards also recorded a higher variation in MOE values compared to the HTD samples, although the difference was negligible.

\section{ACKNOWLEDGEMENTS}

The authors are particularly grateful for the technical support of Mr. Eric Littee, Mrs. Rica Minett, and Mr. Daniel Field for the preparation, processing, and testing of the wood samples. Dr. Rob McGavin is thanked for his suggestions and comments. The support provided by the Queensland Government, Department of Agriculture and Fisheries (DAF), through the provision of the unique facilities located at the Salisbury Research Facility, is acknowledged as critical to facilitate studies of this nature. The authors are also grateful to Hyne Timber, in particular Dr. Henri Bailleres, for the supply of the timber and suggestions for this project. The authors also acknowledge the Australian Research Council

and the Centre for Future Timber Structures (Grant No. IH150100030) for the funding support provided for this research.

\section{REFERENCES CITED}

AS/NZS 1080.1 (2012). "Timber - Methods of test - Moisture content," Standards Australia, Sydney, Australia.

AS/NZS 2796.3 (1999). "Timber - Hardwood - Sawn and milled products timber for furniture components," Standards Australia, Sydney, Australia.

AS/NZS 4787 (2001). "Timber-Assessment of drying quality," Standards Australia, Sydney, Australia.

Bekhta, P., and Niemz, P. (2003). "Effect of high temperature on the change in color, dimensional stability and mechanical properties of spruce wood," Holzforschung 57(5), 539-546. DOI: 10.1515/HF.2003.080

Bond, B. H., and Espinoza, O. (2016). "A decade of improved lumber drying technology," Current Forestry Reports 2(2), 106-118. DOI: 10.1007/s40725-0160034-Z

Cai, L., and Oliveira, L. C. (2008). "Impact of high-temperature schedules on drying of spruce and pine," Drying Technology 26(9), 1160-1164. DOI: 10.1080/07373930802266280

Carnavas, P. and McNaught, A. M. (1991). Optimisation of High Temperature Drying Procedures for Slash Pine, Queensland Forest Service, Araluen, Australia.

Cown, D., Haslett, A. N., Kimberley, M. O., and McConchie, D. L. (1996). "The influence of wood quality on lumber drying distortion," Annals of Forest Science 53(6), 1177-1188. DOI: 10.1051/forest:19960611

Frühwald, E. (2007). "Effects of high drying temperatures and restraint on twist of larch (Larix)," Wood Material Science and Engineering 2(2), 55-65. DOI: 10.1080/17480270701770598

Hartley, J. (1975). "Aspects of the high temperature drying of distortion-prone juvenile 
softwood." Australian Forest Industries Journal 41(7), 55-57.

Herrera-Díaz, R., Sepúlveda-Villarroel, V., Pérez-Peña, N., Salvo-Sepúlveda, L., SalinasLira, C., Llano-Ponte, R., and Ananías, R. A. (2017). "The effect of wood drying and heat modification on some physical and mechanical properties of radiata pine," Drying Technology 36(5), 537-544. DOI: 10.1080/07373937.2017.1342094

Johansson, M., and Kliger, R. (2007). "Influence of material characteristics on warp in Norway spruce studs," Wood and Fiber Science 34(2), 325-336. DOI:

Johansson, M., and Ormarsson, S. (2009). "Influence of growth stresses and material properties on distortion of sawn timber-numerical investigation," Annals of Forest Science 66(6), 1-10. DOI: 10.1051/forest/2009045

Kliger, R., Bengtsson, C., and Johansson, M. (2005). "Comparison between HT-dried and LT-dried spruce timber in terms of shape and dimensional stability," Holzforschung 59(6), 647-653. DOI: 10.1515/HF.2005.104

Koch, P. (1971). "Process for straightening and drying southern pine 2 by 4's in 24 hours," Forest Products Journal 21(5), 17-24.

Kumar, C., and Karim, M. A. (2017). "Microwave-convective drying of food materials: A critical review," Critical Reviews in Food Science and Nutrition 59(3), 379-394. DOI: $10.1080 / 10408398.2017 .1373269$

Kumar, C., Karim, M. A., and Joardder, M. U. H. (2014). "Intermittent drying of food products: A critical review," Journal of Food Engineering 121, 48-57. DOI: 10.1016/j.jfoodeng.2013.08.014

Leggate, W., Kumar, C., McGavin, R. L., Faircloth, A., and Knackstedt, M. (2020). "The effects of drying method on the wood permeability, wettability, treatability, and gluability of southern pine from Australia," BioResources 16(1), 698-720. DOI: 10.15376/biores.16.1.698-720

Mahild (2017). "NZ's first operational continuous timber drying kiln," (https://fridayoffcuts.com/dsp_article.cfm?id=435\&aid=4374, Accessed on $10^{\text {th }}$ August 2020.

Mishiro, A., and Booker, R. E. (1988). "Warping in new crop radiata pine $100 \times 50 \mathrm{~mm}$ (2 by 4) boards," Bulletin of the Tokyo University Forests 80, 37-68.

Phonetip, K., Ozarska, B., Harris, G., Belleville, B., and Brodie, G. I. (2019). "Quality assessment of the drying process for Eucalyptus delegatensis timber using greenhouse solar drying technology," European Journal of Wood and Wood Products 77(1), 5762. DOI: $10.1007 / \mathrm{s} 00107-018-1364-2$

Rabidin, Z. A., Seng, G. K., and Wahab, M. J. A. (2017). "Characteristics of timbers dried using kiln drying and radio frequency-vacuum drying systems," MATEC Web of Conferences 108, 1-5. DOI: 10.1051/matecconf/201710810001

Redman, A. (2004). Moisture Variation in Dried Hardwood Timber (Project No. PN01.1305), Forest and Wood Products Research and Development Corporation, Melbourne, Australia.

Redman, A. L. (2017). Modelling of Vacuum Drying of Australian Hardwood Species, Ph.D. Dissertation, Queensland University of Technology, Brisbane, Australia.

RStudio (2015). RStudio: Integrated Development for $R$ (Version 1.3.1058), RStudio, Inc., Boston, MA.

Shmulsky, R., Erickson, R. W., Steele, P. H., and Buckner, D. (2005). "Warp reduction of SYP lumber by restrained drying," Forest Products Journal 55(9), 37-41.

Simpson, W. T. (1999). "Drying and control of moisture content and dimensional changes," in: Wood Handbook: Wood as an Engineering Material, R. J. Ross (ed.), 
U. S. Department of Agriculture, Forest Products Laboratory, Madison, WI.

Taylor, F. W., and Mitchell, P. H. (1987). "Drying pine lumber at very high temperatures and air velocities," Wood and Fiber Science 19(3), 239-245.

Terziev, N. and Daniel, G. (2002). "Industrial kiln drying and its effect on microstructure, impregnation and properties of Scots pine timber impregnated for above ground use.

Part 2. Effect of drying on microstructure and some mechanical properties of Scots pine wood," Holzforschung 56(4), 434-439. DOI: 10.1515/HF.2002.067

Thiam, M., Milota, M. R, and Leichti, R. J. (2002). "Effect of high-temperature drying on bending and shear strengths of western hemlock lumber," Forest Products Journal 52(4), 80-89.

USNR (2019). "Counter-flow kiln," (https://www.usnr.com/en/product/counterflowkiln?dt=1), accessed 11 December 2019.

Vasileios, F., Karastergiou, S., Philippou, J., and Andromachi, M. (2017). “Effect of drying method, lumber quality and lumber thickness in the appearence of drying defects in fir lumber," in: Proceedings of the $13^{\text {th }}$ International IUFRO Wood Drying Conference, 13-16 September, Istanbul University, Istanbul, Turkey, pp. 154-162.

Ward, J. C., and Simpson, W. T. (1997). "Drying defects," in: Dry Kiln Operator's Manual, W. T. Simpson (ed.), U. S. Department of Agriculture, Forest Products Laboratory, Madison, WI.

Wellons (2018). Continuous Dry Kiln (CDK), Wellons, USA (http://www.wellons.com/cdkkilnd.html)

Wu, Q., and Smith, W. R. (1997). "Effects of elevated and high-temperature schedules on warp in southern yellow pine lumber," Forest Products Journal 48(2), 52-56.

Yao, J., and Taylor, F. W. (1979). "Effect of high-temperature drying on the strength of southern pine dimension lumber," Forest Products Journal 29(8), 49-51.

Yuniarti, K., Ozarska, B., Harris, G., Brodie, G., and Waugh, G. (2015). "Moisture distribution and defect development during intermittent drying of Eucalyptus saligna," in: Proceedings of the International Conference of Indonesia Forestry Researchers III, 21-22 October, IPB International Convention Centre, Borgor Indonesia, pp. 1-11.

Article submitted: September 24, 2021; Peer review completed: November 14, 2021; Revised version received and accepted: November 22, 2021; Published: November 30, 2021.

DOI: 10.15376/biores.17.1.574-591 